DIVULGAÇÃO DE TRABALHO

\title{
ANÁLISE DAS HABILIDADES COGNITIVAS REQUERIDAS DOS CANDIDATOS AO CARGO DE CONTADOR NA ADMINISTRAÇÃO PÚBLICA FEDERAL, UTILIZANDO-SE INDICADORES FUNDAMENTADOS NA VISÃO DA TAXONOMIA DE BLOOM ANALYSIS OF COGNITIVE SKILLS REQUIRED FROM CANDIDATE ACCOUNTANTS IN THE BRAZILIAN FEDERAL PUBLIC ADMINISTRATION, USING INDICATORS BASED ON BLOOM'S TAXONOMY
}

JORGE JOSÉ BARROS DE SANTANA JUNIOR Mestrando em Ciências Contábeis pelo Programa Multiinstitucional e InterRegional de Pós-Graduação em Ciências Contábeis - UnB/UFPB/UFPE/UFRN E-mail: jorgesantanajr@uol.com.br
DIMMITRE MORANT VIEIRA GONÇALVES PEREIRA

Mestrando em Ciências Contábeis pelo Programa Multiinstitucional e InterRegional de Pós-Graduação em Ciências Contábeis - UnB/UFPB/UFPE/UFRN E-mail: dimmitre@gmail.com

\author{
JORGE EXPEDITO DE GUSMÃO LOPES \\ PhD in Education Administration, Research Scholar \\ University of Miami, Master at Penn State University \\ Professor PHD do Depạttamento de Ciências Contábeis da Universidade Federal de Pernambuco \\ E-mail:jlopes@ufpe.br
}

\section{RESUMO}

O presente estudo objetiva detectar, através dos seis níveis de conhecimento da Taxonomia de Bloom, qual a tendência das habilidades cognitivas requeridas, quando da demanda por profissionais contadores pela Administração Direta e Indireta da União, utilizando-se da análise das questões de algumas recentes provas de concursos (1999 a 2006); o que evidenciará um perfil de desempenho intelectual delineado por esse setor público. A partir dessa análise, busca-se fazer uma reflexão sobre os caminhos a serem percorridos, para que o profissional contador possa atingir as demandas de desempenho intelectual exigidas pelo atual cenário de desenvolvimento tecnológico e econômico mundial. $\mathrm{O}$ artigo foi desenvolvido utilizando-se do método indutivo, mediante pesquisas bibliográficas e documentais, além de técnicas de investigação estatística. Aborda-se o histórico das últimas mudanças ocorridas no mercado profissional, em especial do setor público, e o entendimento dos fundamentos da Taxonomia de Bloom, apresentando como proposta alguns indicadores de aprendizagem mais voltados para uma realidade atual. $O$ resultado da pesquisa demonstrou que não se está exigindo dos candidatos ao cargo de contador (ou com especialidade em contabilidade) os mais altos indicadores de habilidades cognitivas. Verifica-se, portanto, a necessidade de mudanças efetivas nos rumos dessa profissão, para que se possa garantir o espaço almejado para todos aqueles que optaram em trabalhar e desenvolver as Ciências Contábeis.

Palavras-chave: Desafios Profissionais; Profissional Contador; Habilidades Cognitivas; Desempenho Intelectual.

\section{ABSTRACT}

This study aims to detect, by means of the six knowledge levels in Bloom's Taxonomy, tendencies in the cognitive abilities required when professional accountants are demanded by the Brazilian Direct and Indirect Administration, using the analysis of questions posed during some recent selection exams (1999 to 2006), to evidence the intellectual performance profile outlined by the public sector. Based on this analysis, attempts are made to reflect on future measures to allow professional accountants to comply with the intellectual performance demands posed by the current global technological and economic development scenario. The article was developed using the inductive method; through bibliographical and documental research, besides statistical research techniques. The history of the last changes occurred in the professional market is addressed, particularly in the public sector, as well as the understanding of the fundamentals of Bloom's Taxonomy, proposing some learning indicators more directed at current reality. $O$ resultado da pesquisa demonstrou que não se está exigindo dos candidatos ao cargo de contador (ou com especialidade em contabilidade) os mais altos indicadores de habilidades cognitivas. Verifica-se, portanto, a necessidade de mudanças efetivas nos rumos dessa profissão, para que se possa garantir o espaço almejado para todos aqueles que optaram em trabalhar e desenvolver as Ciências Contábeis.

The research results showed that the highest cognitive skill indicators are not being demanded from candidate accountants (or with a specialization degree in accountancy). The need for effective changes are needed in where this profession is heading, in order to guarantee the space wanted by everybody who chose to work in and develop Accountancy.

Keywords: Professional challenges; Professional Accountant; Cognitive Skills; Intellectual Performance. 


\section{INTRODUÇÃO}

Existe uma constante abordagem por parte da literatura e meios de comunicação, de uma forma geral, das crescentes exigências feitas aos profissionais por parte de um mercado globalizado e com tecnologia avançada:

Quando a tecnologia muda, os trabalhos também mudam. A tecnologia requer normalmente mais funcionários com nível superior de instrução para manter o sistema em operação. [...] De modo geral, a tecnologia eleva o nível das exigências práticas e intelectuais da força total de trabalho (DAVIS; NEWSTROM, 2001, p. 103).

À medida que o mundo torna-se mais interligado e os negócios mais complexos e dinâmicos, o trabalho precisa ligar-se em profundidade à aprendizagem. [...] As organizações que realmente terão sucesso no futuro serão aquelas que descobriram como cultivar nas pessoas o comprometimento e a capacidade de aprender em todos os níveis da organização (SENGE, 2003, p. 37).

No caso do profissional contábil não poderia ser diferente. Os avanços tecnológicos e o acelerado processo de mudanças nas relações sociais, além das incertezas nos campos políticos e econômicos, fomentam debates e reflexões sobre o papel presente e futuro dos contadores, conforme aborda Cosenza (2001, p. 61):

Não há dúvida de que a profissão contábil caminha para a intelectualidade, em lugar do exagerado pragmatismo atual. Assim, a atuação do contabilista deverá ultrapassar sua área específica de atuação e se integrar com as diversas áreas de conhecimento aplicado aos negócios, como Economia, Administração, Direito etc. Isto tudo leva a crer que o contador que terá maiores condições de sobreviver, nesse novo milênio, será aquele que se propuser a mover-se da cultura analítica retrospectiva para a visão prospectiva holística, além de estar sempre aberto para aprender novos conceitos.

Em virtude desses aspectos acima mencionados, o moderno profissional deve ser capaz de selecionar dados, fornecer informação, gerar conhecimento e, principalmente, produzir o saber necessário para agir e agregar valores à sua empresa. Não basta ter um bom conhecimento técnico inerente ao seu ofício, é imprescindível gerar recursos estratégicos essenciais para o sucesso e manutenção das organizações.

Apesar da propalada necessidade de a contabilidade proporcionar elementos mais ricos e tempestivos para os seus usuários ou tomadores de decisão, não tenho verificado estudos no sentido de constatar a real exigência do mercado brasileiro quanto às habilidades intelectuais requeridas para um profissional da área contábil.

A denominada Crise do Estado levou o Governo Federal a rediscutir o seu papel, propondo uma Administração Pú- blica mais gerencial, como resposta à expansão das funções econômicas e sociais do Estado, tentando desvencilhar-se de uma estrutura altamente burocrática. A eficiência da administração pública, a necessidade de reduzir custos e aumentar a qualidade dos serviços, tendo o cidadão como beneficiário, tornou-se, então, essencial.

Nesse sentido, o servidor público que antes era completamente voltado para dentro da organização, para as suas normas e regulamentos internos, passou a ser exigido gradativamente no sentido de apresentar uma nova postura profissional, como reflexo desse processo de mudanças, que primeiramente foi percebido e iniciado pelos funcionários das empresas privadas.

O profissional contábil não está isento desse processo de mudanças no perfil exigido pelo mercado. Seja na iniciativa privada, ou no setor público, o contador é constantemente desafiado a tomar ou sugerir decisões estratégicas importantes para o futuro da organização.

Se uma boa escolha de pessoal qualificado para exercer determinada função começa em um adequado processo de seleção, que permita o ingresso na instituição de um profissional com capacidade de habilidades cognitivas em todos os níveis, suficientes para a realização das tarefas mais simples até as mais complexas, exigindo a sua criatividade e o seu espírito crítico abalizado, analisar alguns aspectos desse processo de seleção torna-se de interesse relevante.

Portanto, não basta o reconhecimento da necessidade de um novo perfil dos profissionais do presente século, em especial do contador, é necessário verificar se as organizações estão se utilizando de mecanismos seletivos mais apropriados nas provas de concurso público, que garantam uma renovação qualitativa no seu quadro de pessoal. Por sua vez, o profissional contador poderá, através da sinalização de pesquisas e estudos semelhantes a este, organizar e direcionar os seus objetivos de estudo e aprendizagem mais voltados para uma produção intelectual elevada e consistente.

Dentro dessa perspectiva, a pesquisa procurou avaliar o processo de seleção dos contadores para a Administração Pública, com base em uma tradicional teoria de aprendizagem: A Taxonomia de Bloom.

Este estudo foi inspirado no trabalho de Davison e Baldwin (2005), que procuraram identificar a tendência na demanda cognitiva inerente aos finais dos capítulos dos livros de ensino (EOC) de contabilidade intermediária, através da Taxonomia de Bloom. Esses autores tiveram, como principal resultado, uma constatação de que não houve uma mudança positiva significativa, ao longo de várias décadas, em material de EOC, considerando os níveis mais altos da Taxonomia de Bloom.

Conforme Anderson et al. (2001), o trabalho de Bloom foi pela primeira vez publicado em 1956 e, desde a sua primeira publicação, esse trabalho tem fornecido uma base sólida no desenvolvimento de currículos (o que ensinar) e nos projetos de avaliação (o que medir). Não se trata, 
portanto, de uma ferramenta ultrapassada, mas que deva ser adaptada dentro da base de evolução do conhecimento da sociedade, considerando os aspectos geográficos e culturais. Nas palavras de Bloom (1972, p. 28): "O conhecido em 1955 não foi conhecido do mesmo modo em épocas anteriores e provavelmente sofrerá algumas modificações no futuro".

Por tudo isso e considerando os desafios de uma sociedade cada vez mais globalizada e exigente, diante dos problemas que se apresentam no cenário econômico mundial, a pergunta que se coloca é a seguinte: os processos de seleção dos futuros contadores da Administração Direta e Indireta da União têm requerido as mais altas habilida- des de domínio cognitivo, que proporcionem o ingresso no setor público de um profissional com capacidade de tratar os assuntos de forma criativa e com a avaliação crítica necessária?

A resposta a essa indagação nos dará uma melhor visão da diferença existente entre o discurso e a realidade. Permitirá que se verifique qual a distância ainda a ser percorrida pelo profissional contador, a fim de transformar a sua carreira em algo mais atrativo e valorizado, através da busca em atingir um patamar mais elevado de desempenho intelectual que possa fazer frente às exigências e desafios deste mundo globalizado.

\section{O QUE É A TAXONOMIA DE BLOOM?}

A taxonomia dos objetivos educacionais, também popularizada como Taxonomia de Bloom, é uma classificação dos níveis de aprendizagem. Foi resultado do trabalho de uma comissão multidisplinar de especialistas de várias universidades dos EUA, liderada por Benjamin S. Bloom, na década de 1950. Foram identificados por essa comissão três domínios educativos: o cognitivo, o emocional e o psicomotor (Figura $1 \boldsymbol{\nabla}$ ). O terceiro não foi terminado e apenas o primeiro foi implementado em sua totalidade.

Pode-se dizer, resumidamente, que o domínio cognitivo é baseado no conhecimento e no desenvolvimento de habilidades intelectuais. O domínio afetivo é a forma como se lida com os problemas emocionalmente, como: sentimentos, valores, entusiasmo, motivação e atitudes. Por fim, o domínio psicomotor verifica as habilidades motoras em termos de velocidade, precisão, distância, procedimentos ou técnicas de execução.

O artigo procurou avaliar, especificamente, o domínio cognitivo requeridos pelas provas de concurso público. Segundo o Centro de Ciências da Saúde da UFPA (2003, p. 6), o domínio cognitivo é dentre os demais, o mais freqüentemente usado nas avaliações.

Moreira (1999) explica que: "uma Teoria de Aprendizagem é uma construção humana para interpretar sistematicamente a área de conhecimento que chamamos aprendizagem".

Ressalte-se, porém, que a cognição envolve vários processos e produtos mentais complexos, sendo a Taxonomia de Bloom apenas uma simplificação dos níveis de aquisição de conhecimento, numa tentativa de melhorar a percepção do grau de aprendizagem do indivíduo. A natureza da cognição é explicada por Fonseca (2001, p. 25), da seguinte forma:

Em termos multicomponenciais, a cognição envolve, portanto, a contribuição e a coesão-coibição de vários subcomponentes, nomeadamente da atenção, da percepção, da memória, da motivação, da integração e da monitoração central, do processamento seqüencial e simultâneo, da planificação, da resolução de problemas e da expressão e comunicação de informação.

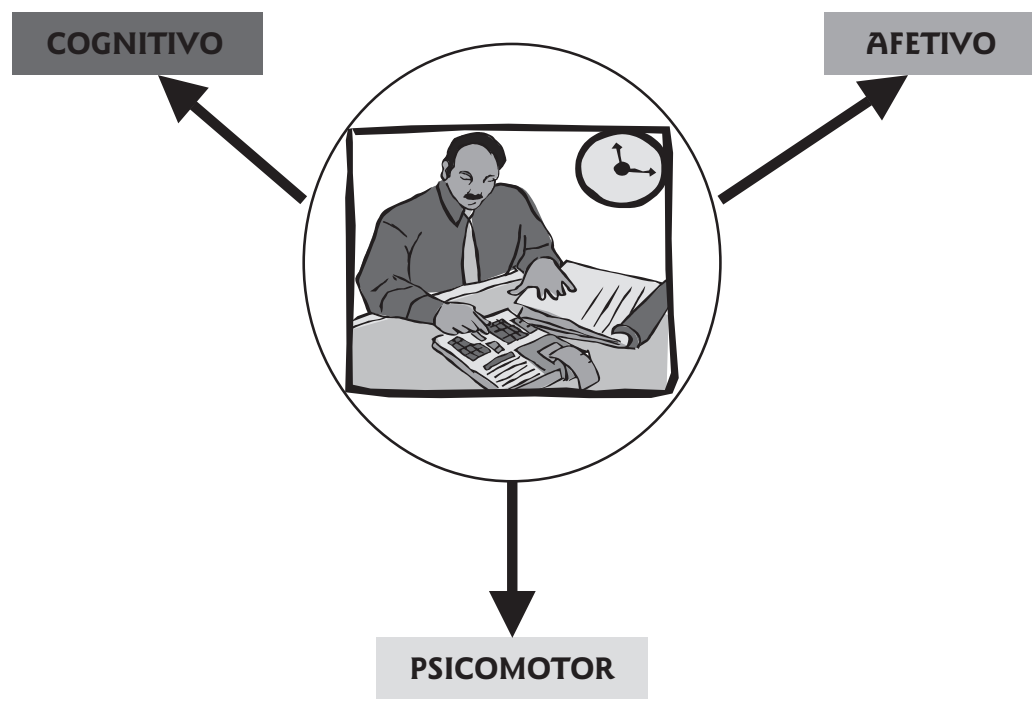

Figura 1 - Os Três Domínios do Processo de Aprendizagem 
O Domínio Cognitivo é subdividido em seis categorias. Cada categoria segue uma linha hierárquica que, geralmente, exige que o indivíduo domine a anterior antes de atingir a próxima desejada. São, portanto, processos intelectuais cumulativos, no qual uma categoria em um nível inferior dá o suporte a uma próxima categoria de nível superior, como se fosse uma escada de seis degraus que a cada passo dá acesso a um patamar de conhecimento mais elevado (Figura 2 ()).

De acordo com Rodrigues Júnior (1997), cada categoria pode ser, assim, distinguida:

1. Conhecimento: Nessa categoria, agrupam-se os processos que requerem que o indivíduo reproduza com exatidão uma informação que lhe tenha sido dada, seja ela uma data, um relato, um procedimento, uma fórmula, ou uma teoria.

2. Compreensão: Essa categoria é a primeira que requer elaboração (modificação) de um dado ou informação original. A elaboração ainda não será de complexidade elevada; o indivíduo deverá ser capaz de usar uma informação original e ampliá-la, reduzí-la, representá-la de outra forma ou prever conseqüências resultantes da informação original.

3. Aplicação: É a categoria que reúne processos nos quais o indivíduo transporta uma informação genérica para uma situação nova e específica.

4. Análise: Processos dessa categoria caracterizam-se por separar uma informação em elementos componentes e estabelecer relações entre eles. Entre ou- tras coisas, o processo de Análise pressupõe identificar aspectos centrais de uma proposição, verificar a sua validade, dos mesmos, constatar possíveis incongruências lógicas.

5. Síntese: É a categoria que representa processos nos quais o indivíduo reúne elementos de informação para compor algo novo que terá, necessariamente, traços individuais distintos.

6. Avaliação: Representa os processos cognitivos mais complexos. Basicamente, o processo de avaliar consiste na confrontação de um dado, de uma informação, de uma teoria, de um produto etc., com um critério ou conjunto de critérios, que podem ser internos ao próprio objeto da avaliação ou externos a ele.

A hierarquização entre os dois últimos níveis das categorias do domínio cognitivo da taxonomia de objetivos educacionais não são consenso, ensejando uma discussão sobre a importância maior entre o ser criativo e o ser crítico, porém são considerados os dois mais altos níveis de desenvolvimento intelectual.

A exigência dos níveis 5 e 6 da Taxonomia de Bloom é essencial para quem deseja desenvolver habilidades intelectuais, que levem a uma resolução criativa de problemas diversos e complexos, os quais em muitas situações ainda não se apresentam de forma familiar ao indivíduo, que deve ser capaz de identificá-los e, se possível, antecipar-se aos fatos, encontrando as soluções mais adequadas (DAVIDSON; BALDWIN, 2005).

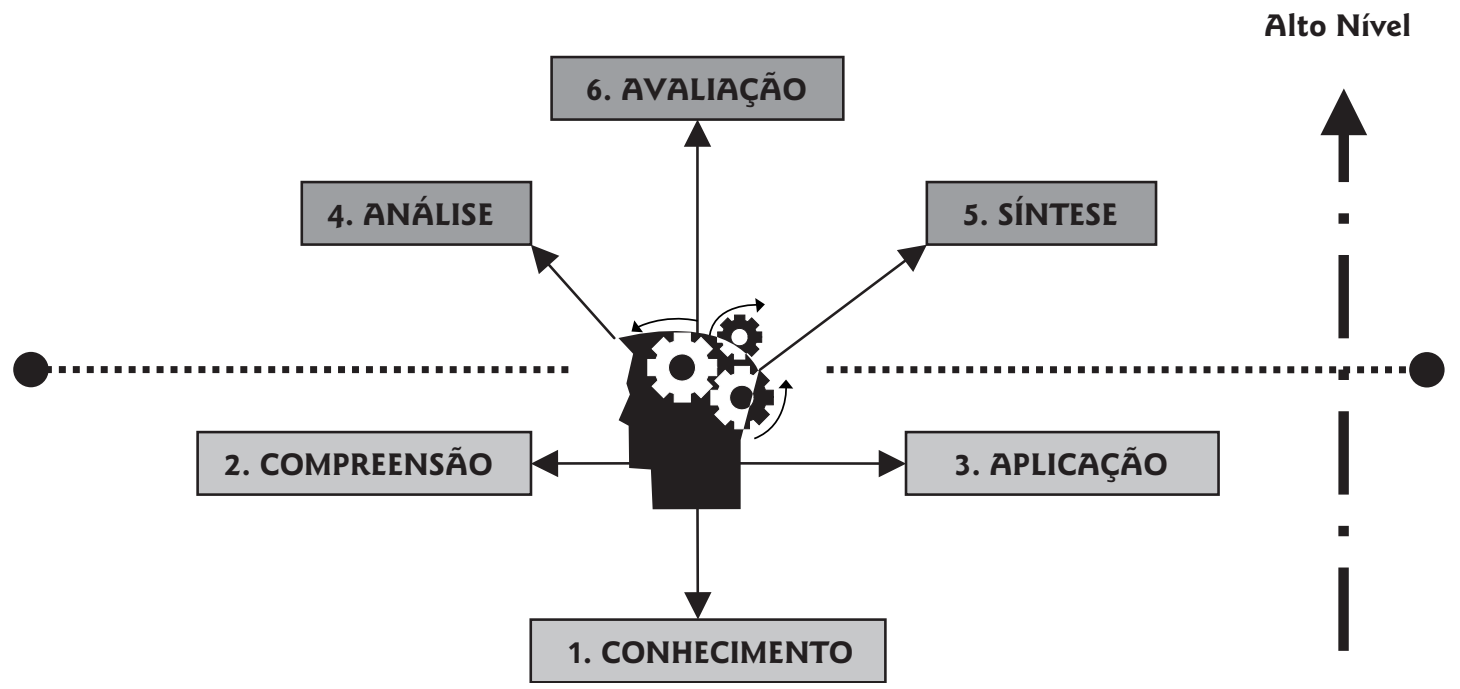

Figura 2 As Seis Categorias dos Domínios de Objetivos Educacionais

\section{EXEMPLOS DE QUESTÕES}

Dentro da amostra da pesquisa realizada, procurou-se selecionar alguns exemplos de questões que abordaram uma das seis categorias do domínio cognitivo, conforme a Taxonomia de Bloom. O resultado está expresso no Quadro $1 \bullet$ : 
A categoria de Análise, em geral, exige a elaboração de questões mais trabalhosas para o candidato, que deverá decompor uma situação proposta em partes distintas, buscando o relacionamento compatível entre elas, além de ter que selecionar os aspectos centrais e essenciais para a resolução do problema.
Entende-se que para uma prova escrita é difícil a elaboração de uma questão na categoria Síntese que não seja de forma dissertativa. É só nesse tipo de questão que o candidato terá a liberdade, dentro de certos critérios de avaliação, de ser testado na sua capacidade de desenvolver um pensamento criativo, coerente e convincente, além

\begin{tabular}{|c|c|c|}
\hline CATEGORIA & QUESTÃO & PROVA \\
\hline 1 Conhecimento & $\begin{array}{l}23 \text { - O regime contábil utilizado pela Contabilidade Pública é: } \\
\text { a) de competência. } \\
\text { b) misto. } \\
\text { c) de caixa. } \\
\text { d) da objetividade. } \\
\text { e) da tempestividade. }\end{array}$ & $\begin{array}{l}\text { Tribunal Regional Eleitoral - Rio Grande } \\
\text { do Norte (2005). Prova para analista } \\
\text { judiciário, área administrativa, especiali- } \\
\text { dade contabilidade. }\end{array}$ \\
\hline 2 Compreensão & $\begin{array}{l}47 \text { - A Lei ñ } 4.320 / 64 \text {, ao classificar as receitas e despesas pú- } \\
\text { blicas de acordo com as categorias econômicas, segregou-as em } \\
\text { corrente e capital. Considerando esta classificação NÃO pode ser } \\
\text { considerada como uma receita de capital aquela que: } \\
\text { a) provenha da alienação de um bem de capital; } \\
\text { b) dê em resultado um bem de capital; } \\
\text { c) esteja na lei definida como operação de capital; } \\
\text { d) possa, por ato do Poder Público, ser vinculada à manutenção e } \\
\text { ao funcionamento de serviços públicos; } \\
\text { e) esteja, por ato do Poder Público, vinculada à constituição ou à } \\
\text { aquisição de bens de capital. }\end{array}$ & $\begin{array}{l}\text { Ministério das Cidades (2005). Cargo } \\
\text { de Contador. }\end{array}$ \\
\hline 3 Aplicação & $\begin{array}{l}24 \text { - Determinada empresa apresentou, em 2004, imposto de } \\
\text { renda a pagar (alíquota de } 15 \% \text { ) de } R \$ 2.400,00 \text {. Sabendo-se } \\
\text { que as bases de imposto de renda e contribuição social são } \\
\text { iguais, a contribuição social sobre o lucro (alíquota de } 9 \% \text { ) devi- } \\
\text { da, em reais, será de: } \\
\text { a) } 216,00 \\
\text { b) } 360,00 \\
\text { c) } 1.440,00 \\
\text { d) } 1.600,00 \\
\text { e) } 3.240,00\end{array}$ & $\begin{array}{l}\text { Petrobrás Distribuidora (2005). Prova } \\
\text { para Contador Pleno. }\end{array}$ \\
\hline 4 Análise & $\begin{array}{l}\text { Assinale a opção correta a respeito desse balancete de verificação } \\
\text { (foi apresentado um balancete com os saldos de } 28 \text { contas). } \\
\text { a) O ativo circulante totaliza } R \$ 58.350 \text {. } \\
\text { b) O patrimônio líquido totaliza } R \$ 53.074 \text {. } \\
\text { c) O passivo circulante totaliza } R \$ 35.799 \text {. } \\
\text { d) O ativo permanente totaliza } R \$ 42.276 \text {. } \\
\text { e) O lucro bruto totaliza } R \$ 12.924 \text {. }\end{array}$ & $\begin{array}{l}\text { Tribunal Regional Eleitoral - Pará } \\
\text { (2005). Prova para analista judiciário, } \\
\text { área administrativa, especialidade } \\
\text { contabilidade. }\end{array}$ \\
\hline 5 Síntese & $\begin{array}{l}\text { (Após o candidato observar } 04 \text { figuras relacionadas às provas } \\
\text { periciais, pede-se) } \\
\text { Redija um texto dissertativo, posicionando-se a respeito do se- } \\
\text { guinte enunciado: CONTRA FATOS, NÃO HÁ ARGUMENTOS. Em } \\
\text { sua argumentação, refira-se, necessariamente, ao que expressam } \\
\text { as figuras acima. }\end{array}$ & $\begin{array}{l}\text { POLÍCIA FEDERAL (2004). Cargo de } \\
\text { Perito Federal - Ciências Contábeis ou } \\
\text { Ciências Econômicas. }\end{array}$ \\
\hline
\end{tabular}




\begin{tabular}{|c|c|c|}
\hline CATEGORIA & QUESTÃO & PROVA \\
\hline 6 Avaliação & $\begin{array}{l}\text { Considerando as idéias apresentadas nos textos da prova objetiva } \\
\text { de Conhecimentos Básicos, que têm caráter unicamente motiva- } \\
\text { dor, e o texto acima, redija um texto dissertativo, desenvolvendo o } \\
\text { seguinte tema: } \\
\text { A contribuição dos avanços científicos para a melhoria da qualida- } \\
\text { de de vida das pessoas } \\
\text { Ao estruturar o seu texto, contemple, necessariamente, os seguin- } \\
\text { tes tópicos: } \\
\text { - na introdução, focalize o tema, relacionando-o apenas ao } \\
\text { contexto brasileiro; } \\
\text { - no desenvolvimento, insira a descrição de uma situação, real } \\
\text { ou fictícia, relacionada ao enfoque dado ao tema, de forma a } \\
\text { exemplificá-lo; } \\
\text { - na conclusão, posicione-se criticamente a respeito da situação des- } \\
\text { crita, vinculando tal posicionamento às idéias do penúltimo pará- } \\
\text { grafo do texto "A crise de valores no mundo contemporâneo". }\end{array}$ & $\begin{array}{l}\text { POLÍCIA FEDERAL (2002). Cargo de } \\
\text { Perito Federal - Ciências Contábeis. }\end{array}$ \\
\hline
\end{tabular}

Quadro 1 Exemplos de questões envolvendo as 06 categorias de domínio cognitivo

de expressar a visão do seu conhecimento pessoal sobre o assunto proposto.

A sexta categoria requer que o candidato tenha que fazer uma avaliação tomando por base um julgamento em termos de evidências internas e/ou externas. O resultado dessa avaliação deverá ser uma opinião crítica, uma conclusão, uma recomendação ou tomada de decisão. Também para essa categoria, verifica-se que o desenvolvimento de uma questão tipo dissertativa seria mais adequada para uma prova escrita. Da análise dos exemplos propostos por Rodrigues Júnior (1997, p. 57), entende-se que uma questão na categoria avaliação, para a área contábil, poderia ser, assim, elaborada: o candidato diante de algumas alternativas de investimento, que exijam um julgamento apurado, deveria se posicionar pela situação mais vantajosa em um determinado cenário econômico.

Os três mais altos níveis da Taxonomia de Bloom, para a classificação das questões de prova realizadas nesta pesquisa, foram examinados pelos seguintes indicadores:

- a questão na categoria Análise deveria estar relacionada com o exame acurado de uma determinada demonstração contábil ou com a análise de uma gama de dados, que resultaria na elaboração de uma demonstração contábil;

- a questão de Síntese deveria exigir do candidato um novo arranjo das partes de uma forma criativa, original e pessoal;

- a questão de Avaliação deveria requerer do candidato a comparação das informações fornecidas com mais de um critério interno e/ou externo, exigindo um julgamento crítico e fundamentado diante de uma situação de avaliação proposta, para determinar a melhor alternativa ou caminho a ser seguido.

Os indicadores propostos não procuram determinar o grau de complexidade das provas de concurso público, uma vez que uma prova com um número grande de questões e que envolvam uma enorme amplitude de conhecimento e compreensão do programa do concurso, pode ser considerada de altíssima dificuldade. Os indicadores propõem-se, no entanto, a revelar se estão sendo requeridas as mais altas habilidades cognitivas dos futuros contadores selecionados, que os ajudarão a enfrentar os atuais desafios exigidos para a profissão.

\section{O NOVO PERFIL EXIGIDO DO SERVIDOR PÚBLICO}

O processo de globalização, caracterizado pela internacionalização de mercados, desregulamentação do fluxo internacional de capitais e pelos impressionantes avanços tecnológicos e científicos, forçou alterações nas relações entre empregador e trabalhador, numa tendência que não é nova no setor privado nacional, porém que na última década atingiu fortemente o setor público. O fator marcante desse processo foi o enfraquecimento do poder do Estado de influir decididamente na condução da política macroe- conômica e de formular e implementar políticas públicas, pela falta de recursos e pela incapacidade de enfrentar a atuação dos grandes conglomerados econômicos multinacionais.

Segundo Alexandrino e Paulo (2002, p. 60):

A partir da década de 90, tem-se observado, no Brasil, uma significativa mudança de mentalidade, ao menos por parte dos detentores do poder político e de 
importantes autores, sobretudo nas áreas econômica e jurídica, no que concerne às relações entre o Estado, especialmente a Administração Pública, e os diversos setores da sociedade.

Cardoso (1997), abordando o tema das conseqüências da globalização e a mudança no papel do Estado, afirmou o seguinte:

A globalização modificou o papel do Estado num outro aspecto. Alterou radicalmente a ênfase da ação governamental, agora dirigida quase exclusivamente para tornar possível as economias nacionais desenvolverem e sustentarem condições estruturais de competitividade em escala global.

[...] um Estado que esteja pronto a transferir para mãos privadas empresas melhor administradas por elas; um Estado, finalmente, no qual os funcionários públicos estejam a altura das demandas da coletividade por melhores serviços.

Como fruto desse debate surgiu no Brasil a proposta de uma administração pública mais gerencial, que teve historicamente a sua base de discussão originada no chamado Plano Diretor da Reforma do Aparelho do Estado - PDRAE (1995), que assim abordou um dos aspectos das propostas de mudança:

Por implicar a flexibilização da estabilidade do funcionalismo, a reforma administrativa tem sido identificada como contrária aos interesses dos servidores. Nada mais incorreto: os bons funcionários, que constituem a maioria absoluta, nada têm a temer. Muito pelo contrário: pretende-se valorizar o servidor público, propiciando-Ihe motivação profissional, remuneração condizente com o mercado de trabalho nacional, além de razoável segurança no emprego. Só assim será restaurada a criatividade, a responsabilidade e a dignidade do servidor público, cuja aspiração maior deve ser a de bem servir a população.
Nem todas as propostas de mudanças sugeridas pelo PDRAE foram implementadas, mas verificou-se que a Emenda da "Reforma administrativa" (Emenda Constitucional n 19/1998) trouxe algumas mudanças nas relações entre o Estado e os agentes públicos, entidades privadas e entidades empresariais, que vêm sendo regulamentadas gradualmente ao longo dos últimos anos.

Os benefícios dessas mudanças, ainda, não se apresentaram de forma consistente e uniforme em todos os entes da federação (União, Estados e Municípios), compreendidos os Poderes Executivo, Legislativo e Judiciário, com as suas respectivas administrações diretas, fundos, autarquias, fundações e empresas estatais. Por sua vez, a Reforma Administrativa foi questionada em alguns pontos por Melo (2000, p. 25), que chegou a dizer: "Se a atual administração do Brasil propusesse uma administração gerencial - este é o sentido teórico da proposta - o Estado teria uma opção pelo cidadão-usuário, para o cidadão-cliente".

Independentemente das críticas sofridas pela proposta de Reforma Administrativa, entende-se que existe uma convergência de pensamento em relação à necessidade de mudanças estruturais no serviço público. Para Figueiredo $e$ Nóbrega (2002, p. 231): "A gestão pública deve conduzir a sua ação de forma a efetuar uma transformação fundamental no comportamento da administração em relação aos seus usuários, passando-o da condição de súdito para a de cidadão, destinatário de toda atividade do Estado”.

As perspectivas de mudanças no setor público é um reflexo de um processo global que se iniciou primeiramente nas empresas privadas, conforme comentou Lima (2003, p. 248): "Da mesma forma como ocorre nas empresas privadas, no setor público de distintos países - e do Brasil, em particular - é possível identificar movimentos de reforma ou mudança organizacional visando tornar o aparelho de Estado mais ágil, flexível e eficaz". Portanto, o servidor público deve estar atento às novas diretrizes propostas para as atividades dos agentes estatais, procurando direcionar os seus esforços na obtenção de novas habilidades que o capacite a enfrentar esses novos desafios, que mais cedo ou mais tarde o alcançarão.

\section{AS HABILIDADES COGNITIVAS ESPERADAS DO CONTADOR}

A análise realizada pela pesquisa referente às questões das provas de concurso no processo de seleção e contratação de pessoal na Administração Pública Federal, em especial para o cargo de contador, procura verificar se a tão mencionada mudança no perfil do funcionário público atingiu essa categoria. Acredita-se que um profissional para estar a altura das demandas da sociedade e poder melhor atender ao cidadão, deve estar apto em toda a sua plenitude e, particularmente, na sua capacidade intelectual, que se refletirá desde o seu adequado processo de seleção até a atingir a sua maturidade na vida profissional. Para isso, é necessária uma melhor reflexão sobre o processo de ensino, aprendizagem e avaliação do contador, que Barros (2005, p. 10), assim, expôs:
Desse modo, percebe-se que a Contabilidade irá até onde seus profissionais puderem levá-la. Sua importância, relevância e valorização dependerão, essencialmente, do conhecimento, das habilidades $e$ atitudes dos profissionais. Existem diversos instrumentos contábeis e uma tecnologia bastante desenvolvida à sua disposição. Indispensável se torna, então, a atuação eficiente e eficaz dos professores que poderão promover o conhecimento necessário, deverão desenvolver as habilidades e incentivar atitudes mais dinâmicas e gerenciais dos futuros contadores. 
Em vista de mudanças cada vez mais aceleradas na sociedade, da intensificação de processos de globalização e da competitividade decorrente desse processo, conhecimentos, aprendizagens e tecnologias passaram a ser ferramentas estratégicas para empresas e corporações (PAZETO, 2005). Portanto, o profissional contador tem pela frente enormes desafios diante da realidade das tecnologias computacionais, que exigirão um uso racional e inteligente da informação, no qual ludícibus (2004, p. 241) destaca as seguintes perspectivas:

1. Haverá ênfase muito grande na análise de tais informações e na seleção do que for: a) indispensável; b) relevante; c) útil, mas não indispensável; d) dispensável; e e) necessário evitar;

2. Poderão ser atendidas com maior precisão as necessidades informativas dos mais variados usuários, porque o modelo decisório será mais explícito;

3. Será possível, assim, a partir do mesmo cadastro básico de informação, elaborar instantaneamente, vários "pacotes" diferentes quanto aos módulos e detalhes, para os vários tipos de usuários. Isso implicará uma decisão sobre a validade de gastar tempo e recursos (no sistema de informação montado) para determinados tipos de usuários e com determinada freqüência.

Observe-se que, nos desafios citados logo acima, fica evidenciada a necessidade do contador possuir habilida- des cognitivas nas categorias de Análise (item 1), Síntese (itens 2 e 3) e Avaliação (itens 1 e 3).

Não se pode mais imaginar a figura do contador como um mero ator dentro do processo de decisão da instituição, o qual só é considerado pela sua capacidade técnica e não gerencial. Nesse aspecto, Cosenza (2001, p. 61) declara:

Não há dúvida de que a profissão contábil caminha para a intelectualidade, em lugar do exagerado pragmatismo atual. Assim, a atuação do contabilista deverá ultrapassar sua área específica de atuação e se integrar com as diversas áreas de conhecimento aplicado aos negócios, como Economia, Administração, Direito etc. Isto tudo leva a crer que o contador que terá maiores condições de sobreviver, nesse novo milênio, será aquele que se propuser a mover-se da cultura analítica retrospectiva para a visão prospectiva holística, além de estar sempre aberto para aprender novos conceitos.

Diante de tudo que já foi exposto, compreende-se que o contador não pode fazer frente às novas tendências voltadas para o setor público e para a sua própria profissão, as quais já são uma realidade presente, se não estiver exercendo os níveis mais altos do desenvolvimento intelectual (análise, criação e crítica).

\section{METODOLOGIA}

O estudo foi desenvolvido utilizando-se do método indutivo, mediante coleta de dados das 37 mais recentes provas de concurso público federal (entre 1999 a 2006), voltadas para profissionais contadores. Para isso, foi realizada uma pesquisa qualitativa e quantitativa, com o auxílio de técnicas de investigação estatística, em que se buscou, através dos indicadores propostos e fundamentados na visão da Taxonomia de Bloom, verificar como se distribuíram as diversas questões de provas dentro dos 06 níveis de habilidades cognitivas.

As questões de provas que se enquadraram nas três primeiras categorias cognitivas foram classificadas como CCA (Conhecimento, Compreensão e Aplicação), as demais foram analisadas, separadamente ou em conjunto, $e$ classificadas como ASA (Análise, Síntese e Avaliação), na busca de analisar a proporção de questões que se apresentaram nos três ou nos dois mais altos níveis das categorias da Taxonomia de Bloom.

A seleção das 37 provas dos concursos foi obtida através do levantamento no banco de dados do jornal eletrônico da Folha Dirigida $<$ www.folhadirigida.com.br $>$ que contava no momento da pesquisa (em: 02/07/2006) com um total de 5.639 provas. Utilizou-se como critério de busca para esse banco de dados a escolha da opção nível Universitário e cargo de Contador. Do resultado obtido (64 provas), foram selecionadas somente as provas de órgãos integrantes da Administração Direta e Indireta da União (25 provas). Posteriormente, foi realizada nova busca no banco de dados utilizando-se para a escolha do cargo a palavra Contabilidade, sendo selecionadas mais 12 provas de um total de 32 obtidas, conforme os mesmos critérios já mencionados.

O resultado da classificação das 1.675 questões da amostra selecionada está apresentado no Apêndice 01 deste trabalho. Ressalte-se que o exame da amostra foi realizado apenas nas questões das provas de conhecimento específico e provas discursivas.

Da observação da única prova de concurso público federal voltada para contadores, que abrangeu todas as categorias do domínio cognitivo, com a finalidade de responder à questão levantada pela pesquisa, foi proposto um percentual de $20 \%$ para a verificação do mínimo necessário que garantiria o atendimento aos três últimos níveis da Taxonomia de Bloom. Nesse caso, considerando-se uma prova de 40 questões, verificar-se-ia a seguinte distribuição mínima: 15\% de Análise (06 questões), 2,5\% de Síntese (01 Questão) e 2,5\% de Avaliação (01 Questão). Esse percentual mínimo esperado contribuiu para a elaboração e respostas de algumas hipóteses levantadas a seguir. 


\section{HIPÓTESES E RESULTADOS DA PESOUISA}

Para responder à primeira e segunda hipótese da pesquisa foram utilizados testes não paramétrico de aderência. Segundo Milone (2004, p. 239):

Um teste de aderência (ou concordância) define a distribuição que melhor descreve a população em estudo (tal como a normal, a binomial, Poisson etc.) mediante a distância entre as freqüências observadas e as teóricas. Se a referida distância é pequena, diz-se que os dados amostrais aderem bem àqueles previstos e 0 modelo adotado é adequado; se grande, a aderência é ruim, e o modelo, impróprio.

\subsection{Hipótese 01}

Após a classificação das 1.675 questões da amostra de 37 provas de concurso federal para os cargos de contador, obteve-se a seguinte distribuição geral, conforme Tabela $1 \mathbf{0}$ abaixo:

Verificou-se que o percentual de questões de provas classificadas nos três últimos níveis da Taxonomia de Bloom, conforme indicadores propostos, alcançaram apenas $8,66 \%$ em relação ao número total de questões. Com base nessa observação foi elaborada a primeira hipótese da pesquisa.

$\mathrm{H}_{0} \Rightarrow$ Os três últimos níveis da Taxonomia de Bloom (Análise, Síntese e Avaliação) são adequadamente exigidos, considerando um percentual mínimo de $20 \%$ esperado, nas provas de concurso público federal para o cargo de contador.

$\mathrm{H}_{1} \Rightarrow$ Os três últimos níveis da Taxonomia de Bloom (Análise, Síntese e Avaliação) NÃO são adequadamente exigidos, considerando um percentual mínimo de $20 \%$ esperado, nas provas de concurso público federal para o cargo de contador.

Com base no teste de aderência entre as quantidades de questões observadas, considerando um percentual mínimo de $20 \%$ para os três últimos níveis da Taxonomia de Bloom, tomando-se como parâmetros um $\alpha=0,05$ e um
Qui-quadrado crítico de $\chi^{2}=3,841$, foi obtido um resultado de $\chi^{2}=134,701$, com $p$-value $<0,0001$. Portanto, rejeita-se a hipótese nula, considerando que os três últimos níveis da Taxonomia de Bloom NÃO são adequadamente exigidos nas provas de concurso público federal para o cargo de contador.

\subsection{Hipótese 02}

Observando-se, ainda, a Tabela 01, verificou-se que o percentual de questões de provas classificadas nos dois últimos níveis da Taxonomia de Bloom, conforme indicadores propostos, alcançaram apenas 0,84\% em relação ao número total de questões. Com base nessa observação, foi elaborada a segunda hipótese da pesquisa.

$\mathrm{H}_{0} \Rightarrow$ Os dois últimos níveis da Taxonomia de Bloom (Síntese e Avaliação) são adequadamente exigidos, considerando um percentual mínimo de $5 \%$ esperado, nas provas de concurso público federal para o cargo de contador.

$\mathrm{H}_{1} \Rightarrow$ Os dois últimos níveis da Taxonomia de Bloom (Síntese e Avaliação) NÃO são adequadamente exigidos, considerando um percentual mínimo de $5 \%$ esperado, nas provas de concurso público federal para o cargo de contador.

Com base no teste de aderência entre as quantidades de questões observadas, considerando um percentual mínimo de $5 \%$ para os dois últimos níveis da Taxonomia de Bloom, tomando como parâmetros um $\alpha=0,05$ e um Quiquadrado crítico de $\chi^{2}=3,841$, foi obtido um resultado de $\chi^{2}=47,152$, com $p$-value $<0,0001$. Portanto, rejeita-se a hipótese nula, considerando que os dois últimos níveis da Taxonomia de Bloom NÃO são adequadamente exigidos nas provas de concurso público federal para o cargo de contador.

\subsection{Hipótese 03}

A Tabela $2 \bullet$ mostra a distribuição das questões de provas nas classificações tipo CCA e ASA por promotoras de concurso público.

Tabela 1 Distribuição Geral Por Categorias

\begin{tabular}{l|c|c} 
Categoria & $\mathbf{N}^{*}$ Questões & \% \\
CCA & 1.530 & 91,34 \\
\hline Análise & 131 & 7,82 \\
\hline Síntese & 10 & 0,60 \\
\hline Avaliação & 4 & 0,24 \\
\hline \hline Total: & $\mathbf{1 . 6 7 5}$ & $\mathbf{1 0 0 , 0 0}$
\end{tabular}

Fonte: Elaborada pelo Autor 
Tabela 2 || Distribuição de Categorias Por Promotoras de Concurso Público Federal

\begin{tabular}{l|r|r|r|c}
\hline Promotora & CCA & $\%$ & ASA & $\%$ \\
\hline Promotoras de concurso público da Administração Direta Federal & 763 & 49,87 & 61 & 42,07 \\
\hline Promotoras de concurso público da Administração Indireta Federal & 767 & 50,13 & 84 & 57,93 \\
\hline Total & 1.530 & 100,00 & 145 & 100,00
\end{tabular}

Fonte: Elaborada pelo Autor

Verifica-se que a Administração Indireta Federal (Empresas, Sociedades de Economia Mista, Fundações e Autarquias, algumas na figura de agências reguladoras) apresenta um resultado um pouco melhor na classificação das questões de provas nos três últimos níveis da Taxonomia de Bloom, possivelmente por estar mais relacionada com o setor privado da economia.

Para avaliar se essa diferença entre a Administração Direta e Indireta da União é significativa, foi utilizada uma análise através de uma Tabela $\mathrm{r} \times \mathrm{c}$ (para 02 linhas e 02 colunas), conforme explicado em Freud e Simon (2000, p. 259), sendo formulada a seguinte hipótese:

$\mathrm{H}_{0} \Rightarrow$ As proporções de questões de provas classificadas nos três últimos níveis da Taxonomia de Bloom (ASA), conforme indicadores propostos, são igualmente elaboradas pelas promotoras de concurso públicos da Administração Direta e Indireta da União.

$\mathrm{H}_{1} \Rightarrow$ As proporções de questões de provas classificadas nos três últimos níveis da Taxonomia de Bloom (ASA), conforme indicadores propostos, Não são igualmente elaboradas pelas promotoras de concurso públicos da Administração Direta e Indireta da União.

Com base no teste da Tabela $\mathrm{r} x \mathrm{c}$, tomando-se como parâmetros um $\alpha=0,05$ e um Qui-quadrado crítico de $\chi^{2}$ $=3,841$, foi obtido um resultado de $\chi^{2}=3,224$, com $p$ - $v a$ lue $=0,0726$. Portanto, não foi possível rejeitar a hipótese nula, constatando-se que a diferença entre as proporções de questões de provas classificadas nos três últimos níveis da Taxonomia de Bloom, conforme indicadores propostos, não são significativos entre as promotoras. Porém, observa-se que o resultado ficou próximo de uma rejeição, o que pode indicar que a Administração Pública Indireta Federal, seguindo uma tendência mais próxima da iniciativa privada, tende para uma avaliação de questões de provas que exigem maiores habilidades cognitivas, apresentando uma quantidade maior de questões nos três últimos níveis da Taxonomia de Bloom.

\subsection{Hipótese 04}

A Tabela 30 mostra a distribuição das questões de provas nas classificações tipo CCA e ASA por organizadoras de concurso público, conforme dados abaixo:

Para verificar se as diferenças das médias de questões tipo ASA entre as organizadoras de concurso público foram significativas, utilizou-se de uma análise de variância. Segundo Lapponi (2005, p. 380): "O objetivo da análise de variância é avaliar se as diferenças observadas entre as médias das amostras são estatisticamente significativas".

Com a finalidade de realizar esse teste foi utilizado a Tabela Anova, conforme explicado em Lapponi (2005, p. 384), sendo formulado a seguinte hipótese:

$\mathrm{H}_{0} \Rightarrow$ As médias das questões de provas classificadas nos três últimos níveis da Taxonomia de Bloom $(A S A)$, conforme indicadores propostos, são

Tabela 3 \Distribuição de Categorias Por Organizadoras de Concurso Público Federal

\begin{tabular}{|c|c|c|c|c|}
\hline ORGANIZADORA & $\mathrm{N}^{\circ}$ PROVAS & Nº QUESTÕES & CCA & ASA \\
\hline CESGRANRIO & 3 & 100 & 82 & 18 \\
\hline \multicolumn{3}{|r|}{$\%$} & 82,00 & 18,00 \\
\hline CESPE & 17 & 1.086 & 1012 & 74 \\
\hline \multicolumn{3}{|r|}{$\%$} & 93,19 & 6,81 \\
\hline FGV & 3 & 100 & 72 & 28 \\
\hline \multicolumn{3}{|r|}{$\%$} & 72,00 & 28,00 \\
\hline NCE & 9 & 241 & 229 & 12 \\
\hline \multicolumn{3}{|r|}{$\%$} & 95,02 & 4,98 \\
\hline Outras & 5 & 148 & 135 & 13 \\
\hline \multicolumn{3}{|r|}{$\%$} & 91,22 & 8,78 \\
\hline TOTAL & 37 & 1.675 & 1.530 & 145 \\
\hline
\end{tabular}

Fonte: Elaborada pelo Autor 
igualmente elaboradas pelas organizadoras de concurso públicos para os cargos voltados para contador na União.

$\mathrm{H}_{1} \Rightarrow$ As médias das questões de provas classificadas nos três últimos níveis da Taxonomia de Bloom $(A S A)$, conforme indicadores propostos, NÃO são igualmente elaboradas pelas organizadoras de concurso públicos para os cargos voltados para contador na União.

Com base no teste da Tabela Anova, tomando-se como parâmetros um $\alpha=0,05$ e um $\mathrm{F}$ crítico de $\mathrm{F}_{\mathrm{c}}=$ 2,668 , foi obtido um resultado de $F_{0}=2,633$, com $p$ value $=0,0523$. Portanto, não foi possível rejeitar a hipótese nula, constatando-se que as diferenças entre as médias de questões de provas classificadas nos três últimos níveis da Taxonomia de Bloom, conforme indicadores propostos, não são significativas entre as organizadoras de concurso público.

\subsection{Hipótese 05}

Para verificar se as diferenças das médias de questões tipo CCA entre as organizadoras de concurso público foram significativas, utilizou-se novamente de uma análise de variância, usando-se a Tabela Anova, conforme elaboração de hipótese a seguir:
$\mathrm{H}_{0} \Rightarrow$ As médias das questões de provas classificadas nos três primeiros níveis da Taxonomia de Bloom (CCA), conforme indicadores propostos, são igualmente elaboradas pelas organizadoras de concursos públicos para os cargos voltados para contador na União.

$\mathrm{H}_{1} \Rightarrow$ As médias das questões de provas classificadas nos três primeiros níveis da Taxonomia de Bloom (CCA), conforme indicadores propostos, NÃO são igualmente elaboradas pelas organizadoras de concursos públicos para os cargos voltados para contador na União.

Com base no teste da Tabela Anova, tomando-se como parâmetros um $\alpha=0,05$ e um $\mathrm{F}$ crítico de $\mathrm{F}_{\mathrm{c}}=2,668$, foi obtido um resultado de $\mathrm{F}_{\mathrm{o}}=3,665$, com $p$-value $=$ 0,0144 . Portanto, rejeita-se a hipótese nula, constatandose que as diferenças entre as médias de questões de provas classificadas nos três primeiro níveis da Taxonomia de Bloom, conforme indicadores propostos, são significativas entre as organizadoras de concurso público federal. Esse resultado indica que as organizadoras de concurso público, para o caso estudado, diferenciaram-se mais em relação à quantidade de questões de provas elaboradas dentro das três primeiras categorias da Taxonomia de Bloom (Conhecimento, Compreensão e Aplicação).

\section{CONCLUSÃO}

Apesar das mudanças propaladas em relação ao novo perfil necessário para o servidor público e, principalmente, para os profissionais de Ciências Contábeis, a pesquisa concluiu que a seleção dos novos contadores na Administração Pública Federal não atende a esse papel mais abrangente requerido pelos desafios impostos pelo cenário econômico e tecnológico globalizado.

Os últimos níveis da Taxonomia de Bloom, conforme os indicadores propostos nesta pesquisa, são pouco requeridos, principalmente aqueles voltados para as habilidades cognitivas que exigem do profissional a capacidade intelectual de criação e de crítica.
As organizações que desejem evoluir e manter-se no cumprimento das suas missões institucionais precisam aprender a aprender. O seu pessoal deve ser capaz de trabalhar em equipes multidisciplinares na busca das soluções. O profissional contador, como parte desse processo, deve inserir-se nesse novo contexto. O contador não deve e não pode deixar-se ser visto apenas como um tecnicista, sem capacidade gerencial administrativa para influir positivamente nos rumos da instituição em que atua. Espera-se que essa pesquisa possa contribuir na reflexão desse tema e na efetiva mudança no perfil da nossa profissão. 


\section{Referências}

ALEXANDRINO, M.; PAULO, V. Direito administrativo. 3. ed. Rio de Janeiro: Impetus, 2002.

ANDERSON, L. W. et al. A taxonomy for learning, teaching and assessing: a revision of Bloom's taxonomy of educational objectives. New York: Longman, 2001.

BARROS, Vaine de Magalhães. O novo e velho enfoque da informação contábil. Revista de Contabilidade e Finanças, São Paulo, n. 38, p. 102-112, Maio/Ago. 2005.

BLOOM, B. S.; ENGELHART, M. D.; FURST, E. J. et al. Taxonomia de objetivos educacionais: domínio cognitivo; tradução de Flávia Maria Sant'Anna. Porto Alegre: Globo, 1972.

BRASIL. Plano Diretor da Reforma do Aparelho do Estado. Brasília, 1995. Disponível em: <http://www.planalto.gov.br>.

CARDOSO, F. H. Conseqüências sociais da globalização. Brasília, 1997. Disponível em: < http//www.planalto.gov.br > .

COSENZA, J. P. Perspectivas para a profissão contábil num mundo globalizado: um estudo a partir da experiência brasileira. Revista Brasileira de Contabilidade, Brasília, n. 130, p. 43-63, jul./ago. 2001.

DAVIS, K.; NEWSTROM, J. W. Comportamento humano no trabalho; tradução de Eunice Laçava Kwasnicka. São Paolo: Pioneira Thomson Learning, 2001.

DAVISON, R. A.; BALDWIN, B. A. Cognitive skills objectives in intermediate accounting textbooks: evidence from end-of-chaper material.Journal of Accounting Education, USA, 23 ed, p. 79-95, 2005.

FIGUEIREDO, C. M.; NOBREGA, M. et al. Administração pública - direito administrativo, financeiro e gestão pública: práticas, inovações e polêmicas._São Paulo: Editora Revista dos Tribunais, 2002:

FREUND, J. E.; SIMON, G. A. Estatística aplicada: economia, administração e contabilidade. 9. ed. Porto Alegre: Bookman, 2000.

FONSECA, V. Cognição e aprendizagem. Lisboa: Âncora, 2001.

IUUDÍCIBUS, S. Teoria da contabilidade. 7. ed. São Paulo: Atlas, 2004.

LAPPONI, R. C. Estatística usando excel. Rio de Janeiro: Elsevier, 2005.

LIMA, S. M. V. Mudança organizacional: teoria e gestão. Rio de Janeiro: Editora FGV, 2003.

MELO, J. T. A. Reformas: administrativa, previdenciária, do judiciário. Belo Horizonte: Del Rey, 1999.

MiLONE, G: Estatística: geral e aplicada. São Paulo: Pioneira Thomson Learning, 2004.

MOREIRA, M. A. Teorias de aprendizagem. São Paulo: EPU, 1999.

PAZETO, A. A. Universidade; formação e mundo do trabalho: superando a visão corporativa. Ensaio: Aval. Pol. Educ., Rio de Janeiro, v. 13 , n. 49 , p. 487-496, out./dez. 2005.

RODRIGUES JÚNIOR, J. F. A taxonomia de objetivos educacionais: um manual para o usuário. 2. ed. Brasília: Editora Universitária de Brasília, 1997.

SENGE, P. M. A quinta disciplina: arte e prática da organização da aprendizagem. 16. ed. São Paulo: Best Seller, 2004.

UNIVERSIDADE FEDERAL DO PARÁ. Elaboração de avaliações - um manual para orientação aos professores do Centro de Ciências da Saúde da UFPA. Belém, 2003.

\section{NOTA - Endereço dos autores}

Universidade Federal de Pernambuco

Centro das Ciências Sociais Aplicadas - CCSA

Departamento de Ciências Contábeis

Av. dos Economistas, $\mathrm{S} / \mathrm{n}^{\circ}-1^{\circ}$ andar

Recife - PE

50740-580 


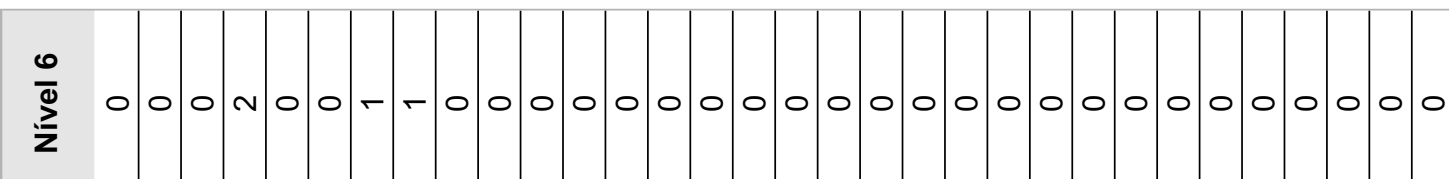

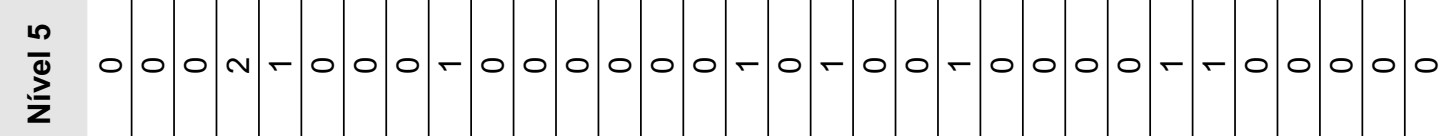

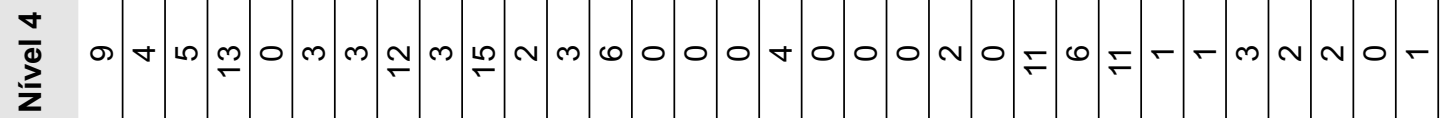

芯

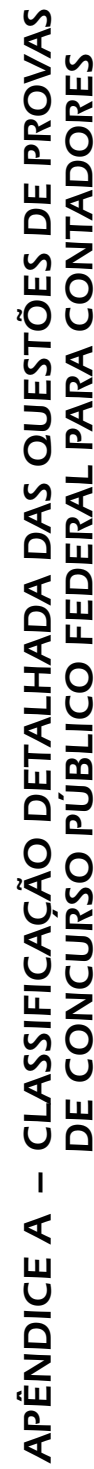

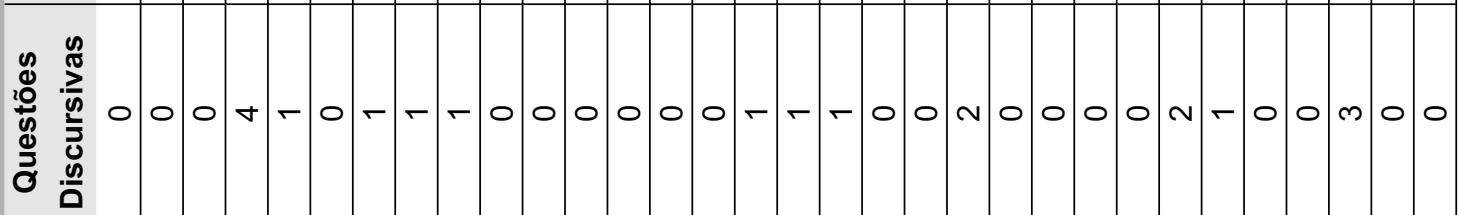

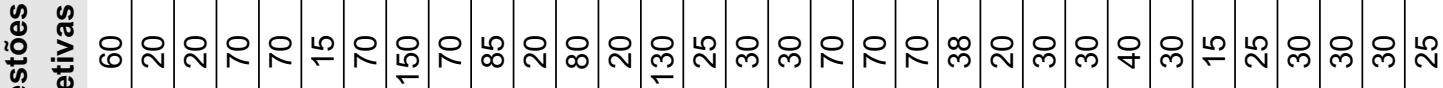
वे $\frac{0}{0}$

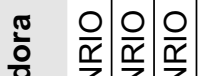

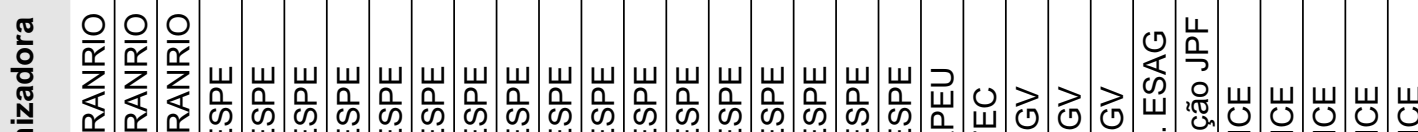 こ D ठ

¿
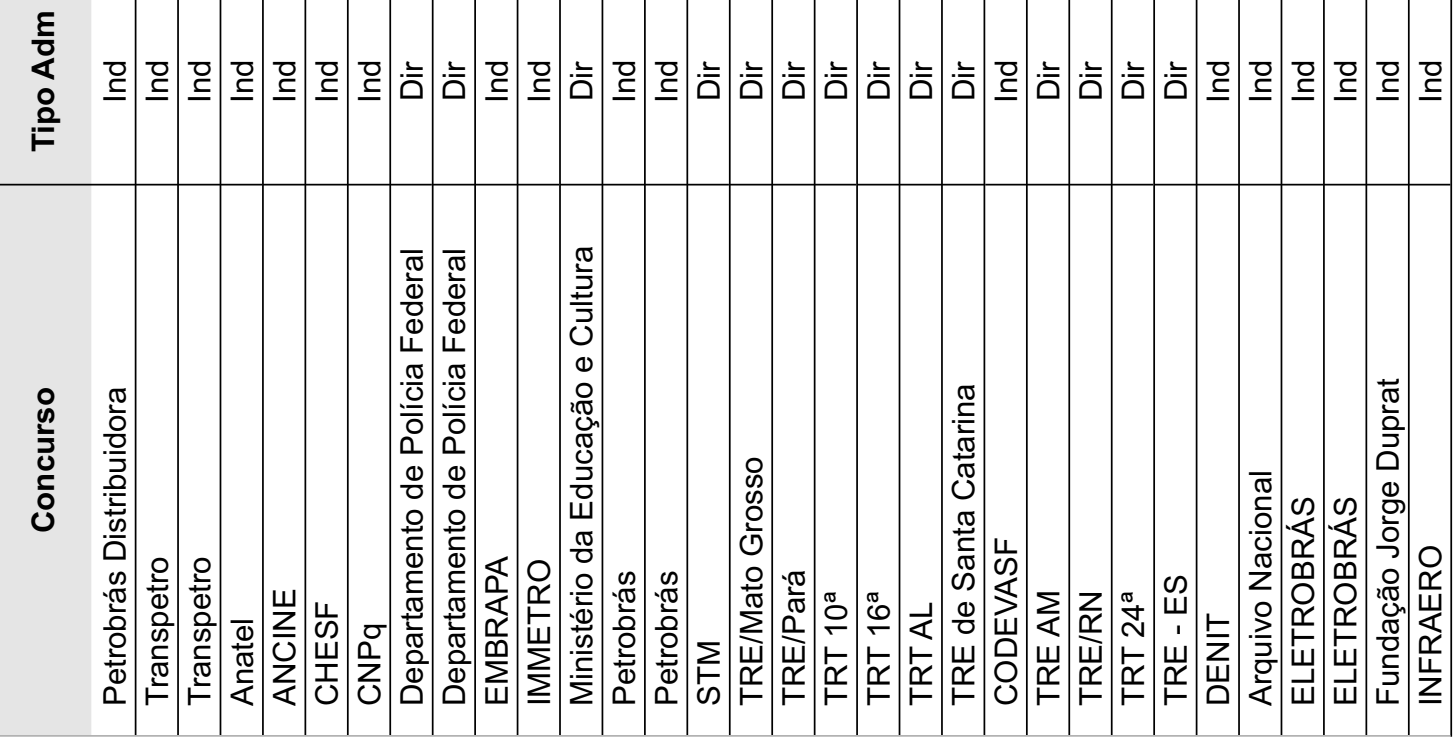


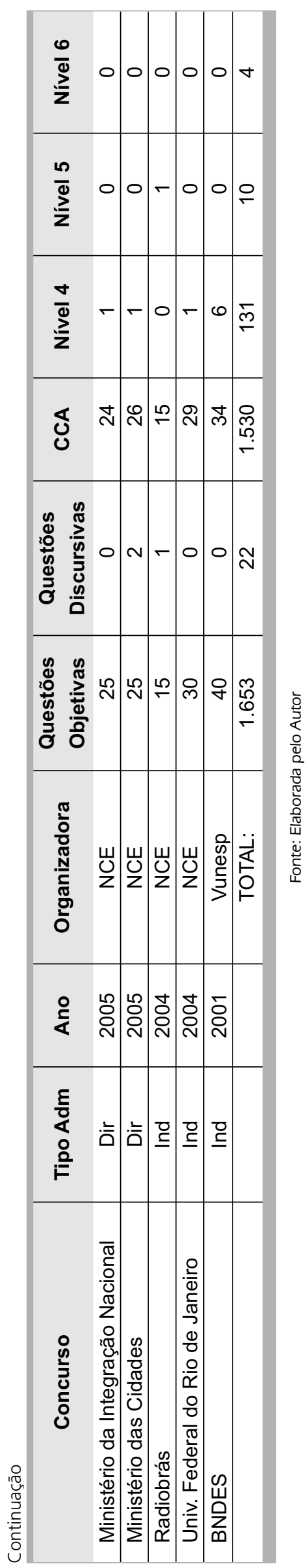

